\title{
Lurasidone Sensitizes Cancer Cells to Osimertinib by Inducing Autophagy and Reduction of Survivin
}

\author{
SHUHEI SUZUKI ${ }^{1,2}$, MASAHIRO YAMAMOTO ${ }^{1}$, TOMOMI SANOMACHI ${ }^{1,2}$, KEITA TOGASHI $^{1,3}$, \\ SHIZUKA SEINO ${ }^{1}$, ASUKA SUGAI $^{1}$, TAKASHI YOSHIOKA ${ }^{2}$, MASASHI OKADA ${ }^{1}$ and CHIFUMI KITANAKA ${ }^{1,4}$ \\ Departments of ${ }^{1}$ Molecular Cancer Science, ${ }^{2}$ Clinical Oncology and \\ ${ }^{3}$ Opthalmology and Visual Sciences, Yamagata University School of Medicine, Yamagata, Japan; \\ ${ }^{4}$ Research Institute for Promotion of Medical Sciences, Yamagata University Faculty of Medicine, Yamagata, Japan
}

\begin{abstract}
Background/Aim: Epidermal growth factor receptor tyrosine kinase inhibitors (EGFR-TKIs) are key drugs in cancer treatment due to their minor adverse effects and outstanding anticancer effects. However, drugs for overcoming EGFR-TKI resistance are not in clinical use so far. Therefore, to overcome resistance, we focused on lurasidone, a new antipsychotic drug, due to its mild adverse effect profile from the viewpoint of drug repositioning. Materials and Methods: We explored the effects of lurasidone alone or in combination with EGFR-TKI on the growth of osimertinib-resistant cancer cells the anti-apoptotic marker expression such as survivin, and autophagy levels by $L C-3 B$ expression. Results: Within a nontoxic concentration range in normal cells, lurasidone and osimertinib combination therapy showed a growth-inhibitory effect in osimertinib-resistant cancer cells in vitro and in vivo. Furthermore, lurasidone decreased survivin expression and mildly induced autophagy. Conclusion: Lurasidone may increase the sensitivity to osimertinib in osimertinib-resistant cancer cells in drug repurposing.
\end{abstract}

Cancer is one of the major causes of mortality and remains an important social burden worldwide. However, there is no true cure for cancer to this day (1). Recent targeted therapies, such as entrectinib and alectinib, which are specific to important molecules in tumors, such as tyrosine receptor kinase (TRK) and anaplastic lymphoma kinase (ALK), are shown to be highly effective $(2,3)$. Osimertinib is a third-

This article is freely accessible online.

Correspondence to: Shuhei Suzuki, Department of Molecular Cancer Science, Yamagata University School of Medicine, Yamagata, 990-9585, Japan. Tel: +81 236285214, Fax: +81 236285215, e-mail: s-suzuki@med.id.yamagata-u.ac.jp

Key Words: Drug repositioning, osimertinib, mental illnesses, survivin, autophagy, chemotherapy, drug resistance. generation epidermal growth factor receptor (EGFR) tyrosine kinase inhibitor (EGFR-TKI) that targets EGFR mutation, and is commonly used worldwide as it is highly effective and causes only minor adverse events $(4,5)$. However, the effect of EGFR-TKIs has only been demonstrated in EGFRmutated lung cancer. Although they only cause minimal adverse events and can cross the blood-brain barrier to act against brain metastases (6), EGFR-TKIs have not been widely used in the clinical setting. In fact, EGFR-TKI (erlotinib) has little antitumor effect against pancreatic cancer and is rarely used in practice (7).

As described in a recent study (8), lurasidone is an antagonist for $\mathrm{D} 2,5-\mathrm{HT}_{7}$, and 5- $\mathrm{HT}_{2 \mathrm{~A}}$ and has been used worldwide as one of the first-line therapies for depression and psychosis. It is well-tolerated in patients as it has little impact on metabolism. Since cancer is a challenging disease with a high risk of mortality, many cancer patients experience depression-like symptoms and require treatment with antidepressants (9).

We have previously examined the effects of antidepressants and antipsychotic drugs, such as aripiprazole, olanzapine, and brexpiprazole, and demonstrated that they reduce the "stemness" properties of cancer stem cells and suppress drugresistance against anticancer agents (10-14). Similar to these drugs, lurasidone may have wider applications and may be welltolerated in frail cancer patients. There are also several challenges to enable the use of these agents in cancer patients; for example, olanzapine is not indicated for use in patients with diabetes, and aripiprazole has minor sedative effects. However, these agents have not been used as an anti-cancer drug in clinical settings. In the present study, we examined the effect of lurasidone on osimertinib-resistant cancer cells.

\section{Materials and Methods}

Antibodies and reagents. Anti- $\beta$-actin (A1978) antibody was purchased from Sigma (St. Louis, MO, USA). Anti-Survivin (\#2808) and anti-LC3 (\#3868) antibodies were from Cell Signaling Technology, Inc. (Beverly, MA, USA). Osimertinib and YM155 were purchased from ChemScene LLC. (Monmouth Junction, NJ, 
USA) and dissolved in dimethyl sulfoxide (DMSO) to $10 \mathrm{mM}$ and $20 \mu \mathrm{M}$, respectively, as stock solutions. Lurasidone was from Cayman Chemical Company (Ann Arbor, MI, USA) and was dissolved in DMSO to $20 \mathrm{mM}$ as a stock solution. 3-Methyladenine (3-MA) was from Merck Millipore (Darmstadt, Germany) and dissolved in DMSO to $75 \mathrm{mM}$ as a stock solution.

Cell culture. The A549 human NSCLC cell line was obtained from the Riken BioResource Center (Tsukuba, Japan). The PANC-1 human pancreatic cancer cell line was from the Cell Resource Center for Biomedical Research, Institute of Development, Aging and Cancer, Tohoku University (Sendai, Japan). The A549 and PANC-1 cells were cultured in DMEM/F12 medium. These cell culture media were supplemented with $10 \%$ fetal bovine serum (FBS), 100 units $/ \mathrm{ml}$ of penicillin, and $100 \mu \mathrm{g} / \mathrm{ml}$ of streptomycin. The establishment of CSC lines from A549 and PANC-1 (A549 CSLC and PANC-1 CSLC, respectively) was previously reported $(15,16)$. A549 CSLC and PANC-1 CSLC authenticity was verified by the genotyping of short tandem repeat (STR) loci (Bio-Synthesis, Inc., Lewisville, TX, USA) and comparisons with the ATCC STR database for Human Cell Lines. GS-NCC01 and GS-Y03 are CSC lines established from a glioblastoma patient and these CSCs were cultured as previously described $(13,17)$. In brief, these CSCs were cultured on collagen I-coated dishes (IWAKI, Tokyo, Japan) in a stem cell culture medium [DMEM/F12 medium added with 1\% B27 supplement (Gibco-BRL, Carlsbad, CA, USA), $20 \mathrm{ng} / \mathrm{ml}$ of EGF and $\mathrm{FGF}_{2}$ (PeproTech Inc., Rocky Hill, NJ, USA), D-(+)-glucose (final concentration, 26.2 $\mathrm{mM}$ ), L-glutamine (final concentration, $4.5 \mathrm{mM}$ ), 100 units $/ \mathrm{ml}$ of penicillin, and $100 \mu \mathrm{g} / \mathrm{ml}$ of streptomycin]. The stem cell culture medium was changed every 3 days, and EGF and $\mathrm{FGF}_{2}$ were added every day. IMR-90 cells, normal human fetal lung fibroblasts, were purchased from the American Type Culture Collection and cultured in DMEM/F12 supplemented with $10 \%$ FBS, 100 units $/ \mathrm{mL}$ penicillin, and $100 \mu \mathrm{g} / \mathrm{ml}$ streptomycin. All experiments with IMR90 were performed within a low passage number (less than six).

Cell viability assays. Viable and dead cells were identified by their ability and inability to exclude vital dyes, respectively $(10,16)$. In brief, harvested cells were stained using $0.2 \%$ trypan blue as a vital dye, and the numbers of viable and dead cells were counted using a hemocytometer. The percentage of dead cells (\%) was defined as $100 x$ 'the number of dead cells'/('the number of viable cells' + 'the number of dead cells').

Immunoblot analysis. Cells were washed with PBS and lysed in RIPA buffer [10 mM Tris- $\mathrm{HCl}$ (pH 7.4), 0.1\% SDS, $0.1 \%$ sodium deoxycholate, $1 \% \mathrm{NP}-40,150 \mathrm{mM} \mathrm{NaCl}, 1 \mathrm{mM}$ EDTA, $1.5 \mathrm{mM}$ Na3VO4, $10 \mathrm{mM} \mathrm{NaF}, 10 \mathrm{mM}$ sodium pyrophosphate, $10 \mathrm{mM}$ sodium $\beta$-glycerophosphate, and $1 \%$ protease inhibitor cocktail set III (Sigma)]. After centrifugation for $10 \mathrm{~min}$ at $14,000 \times g$ at $4^{\circ} \mathrm{C}$, the supernatants were harvested as the cell lysates, and the protein concentration of the cell lysates was measured using a BCA protein assay kit (Thermo Fisher Scientific). Cell lysates containing equal amounts of protein were separated by SDS-PAGE and transferred to polyvinylidene difluoride membranes. The membranes were probed with primary antibodies followed by an appropriate HRP-conjugated secondary antibody according to the manufacturer's protocol. The immune-reactive bands were visualized with Immobilon Western Chemiluminescent HRP Substrate (Merck Millipore) and ChemiDoc Touch Imaging System (Bio-Rad, Hercules, CA, USA).
Immunofluorescence analysis. The protocol of the immunofluorescence analysis was modified from a previous study (18). In brief, A549 cells were seeded on coverslips in 35-mm dishes and used in the experiments. After the cells were fixed with $4 \%(\mathrm{w} / \mathrm{v})$ paraformaldehyde at room temperature (RT) for $10 \mathrm{~min}$ and washed with PBS three times, they were permeabilized and blocked with $0.4 \%$ Triton X-100/2\% FBS in PBS at RT for 10 min. After being washed with PBS three times, the cells were incubated with a primary antibody in PBS containing 2\% FBS at RT for 60 min and then incubated with Alexa Fluor 488-conjugated secondary antibody (A11034, Thermo Fisher Scientific) and Hoechst $33342(10 \mu \mathrm{g} / \mathrm{ml})$ in the same buffer at RT for $10 \mathrm{~min}$. Fluorescent images were acquired using a confocal laser-scanning microscope (FLUOVIEW FV10i: OLYMPUS, Tokyo, Japan).

Gene silencing by siRNA. siRNAs against human survivin (BIRC5 \#2; HSS 179404, \#3; HSS 179405) and Medium GC Duplex \#2 of Stealth RNAi ${ }^{\mathrm{TM}}$ siRNA Negative Control Duplexes (non-targeting) were purchased from Thermo Fisher Scientific. The cells were transiently transfected with RNAs using Lipofectamine RNAiMAX $^{\text {TM }}$ (Thermo Fisher Scientific).

Mouse study. The mouse xenograft study was carried out as previously described $(14,19)$. After anesthetization (intraperitoneal injection of medetomidine, midazolam, and butorphanol at $0.3 \mathrm{mg}$, $4 \mathrm{mg}$, and $5 \mathrm{mg}$ per $\mathrm{kg}$, respectively), A549 CSLCs $\left(1 \times 10^{5}\right)$ suspended in $200 \mu \mathrm{l}$ PBS were implanted subcutaneously in the flank region of 7-week-old male BALB/cAJcl-nu/nu mice (CLEA Japan, Inc., Tokyo, Japan). The tumor volume was assessed by measuring the tumor diameters using calipers and calculated as the larger diameter $\times$ smaller diameter $\times$ smaller diameter. For the systemic administration of drugs, stock solutions of lurasidone (2 $\mathrm{mg} / \mathrm{ml})$ and osimertinib (2 $\mathrm{mg} / \mathrm{ml})$ were diluted in DMSO to prepare $150 \mu \mathrm{l}$ solutions for each injection. Lurasidone was administered by oral gavage to mice at $10 \mathrm{mg} / \mathrm{kg}$ five times a week and osimertinib was orally administered at $5 \mathrm{mg} / \mathrm{kg}$ also five times a week. The drug treatment was started 12 days after tumor implantation and confirmation of subcutaneous tumor formation (approximate average: $25 \mathrm{~mm}^{3}$ ), and similar-sized-tumor-bearing mice were randomized into four groups before the initiation of drug treatment. All animal experiment protocols were approved by the Animal Research Committee of Yamagata University.

Statistical analysis. The results are expressed as the means and standard deviation (SD). The differences were compared using the two-tailed $t$-test. $p$-Values $<0.05$ were considered significant and indicated with asterisks.

\section{Results}

Lurasidone sensitizes various cancer cells to osimertinib. We first examined whether lurasidone sensitizes cancer cells to osimertinib. Various cancer cells, cancer stem cells, and patient-derived glioma cells were treated with lurasidone and osimertinib to measure cell viability. As shown in Figure 1, osimertinib-resistant cancer cells, cancer stem cells, and patient-derived glioma stem cells were sensitized by the addition of lurasidone. We then treated normal human fibroblast IMR-90 cells with lurasidone and measured their 
viability in order to examine the cytotoxicity of lurasidone against normal cells. As shown in Figure 2, lurasidone had little toxicity against normal cells. These findings indicate that lurasidone sensitizes various cancer cells, cancer stem cells, and patient-derived glioma cells to osimertinib in vitro without negatively impacting normal cells.

Lurasidone sensitizes cancer cells to osimertinib by reducing the expression of survivin. Next, we examined the mechanisms by which lurasidone sensitizes cancer cells to osimertinib. A number of molecular and/or cellular mechanisms are involved in determining the sensitivity and resistance to EGFR-TKIs; these mechanisms include increased expression of c-MET (20), emergence of resistance genes (21), modulation of autophagy (18) and expression of survivin, an anti-apoptotic molecule (22, 23). We previously demonstrated that cells can be sensitized to EGFR-TKIs via reduced expression of survivin $(13,14)$. Thus, we focused our examination on the expression of survivin. Specifically, various cancer cells, cancer stem cells, and patientderived glioma cells were treated with lurasidone alone, and the expression of survivin was examined by immunoblotting. As shown in Figure 3, the expression of survivin was reduced when cells were treated with lurasidone. We also knocked-down the expression of survivin in A549 lung cancer cells and subsequently treated them with osimertinib to measure cell viability. As shown in Figure 4, the expression of survivin was reduced and sensitivity to osimertinib was elevated. Lastly, cells were treated with osimertinib and YM155, a pharmacological suppressor of survivin, to measure cell viability. As shown in Figure 5, the expression of survivin was reduced and sensitivity to osimertinib was elevated.

Lurasidone partially sensitizes cells to osimertinib by increasing autophagy. Since we previously demonstrated that increased autophagy led to the sensitization of cells to EGFR-TKIs (18), we treated various cells with lurasidone alone and performed immunoblotting to examine the level of autophagy. As shown in Figure 6A, treatment with lurasidone led to an increase in LC3B expression. Similarly, immunostaining of cells after lurasidone treatment revealed a localized increase in cytoplasmic staining (Figure 6B). Cells were also treated with an autophagy inhibitor, 3-MA, to partially block autophagy induced by lurasidone, and were subsequently treated by osimertinib to measure cell viability. As shown in Figure 6C-D, there was a slight reduction in the sensitivity of cells to osimertinib. Collectively, these findings indicate that lurasidone may sensitize cells to osimertinib by increasing autophagy.

Lurasidone sensitizes tumors to osimertinib in vivo. Our in vitro results indicated that lurasidone enhances the sensitivity of cells to osimertinib by mechanisms such as the reduction of survivin expression. Thus, an animal study was performed in order to determine whether the findings in vitro can be replicated in vivo. A549 CSLCs were injected subcutaneously in both sides of the flanks of nude mice. After tumor formation, the mice were categorized into 4 groups ensuring that the average tumor size was similar across the groups. After administration of lurasidone and osimertinib, we monitored the size of the tumors as well as the overall health of mice including body weight. As shown in Figure 7, administration of the combination of lurasidone and osimertinib was effective in suppressing tumor growth compared to individual drugs alone. Although a nonsignificant weight loss was observed soon after osimertinib treatment, the weight recovered relatively early during the observation period. These findings indicate that lurasidone sensitizes cancer cells to osimertinib in vitro as well as in vivo.

\section{Discussion}

EGFR-TKIs are considered one of the most important antitumor agents as they are highly effective and only cause mild adverse events. In particular, a third-generation EGFR-TKI, osimertinib, is used as a worldwide standard due to its efficacy and cytotoxicity $(4,5)$. However, osimertinib is not effective in certain cancer types, such as A549 lung cancer with wild-type EGFR, and other histological types that are resistant to osimertinib. Thus, there is a need for a novel treatment strategy to overcome resistance to osimertinib in EGFR-TKI-resistant cancer types. Lurasidone is a clinically approved drug and widely used against bipolar disorder and schizophrenia as it is well-tolerated. It was particularly designed to reduce side-effects as it acts as a $5-\mathrm{HT}_{7}$ antagonist and has a low affinity to $\mathrm{H} 1(8,24)$. Thus, it may also be well-tolerated in frail cancer patients. Furthermore, since cancer patients often suffer from depressive symptoms (9), lurasidone may be proposed as a treatment strategy aimed at improving the physical and mental health of cancer patients as it can have both anticancer and anti-depression effects. Notably, it is already approved for clinical use and is an attractive target for drug repositioning (repurposing), which is an inexpensive strategy requiring a relatively short time until approval is granted for another indication in clinical practice $(25,26)$. Collectively, lurasidone may be an attractive option for the treatment of cancer. In the present study, we used an animal model to evaluate the antitumor effect of lurasidone in combination with osimertinib. When we take the human equivalent dose $[\mathrm{HED}=$ animal dose in $\mathrm{mg} / \mathrm{kg} \bullet(\text { animal weight in } \mathrm{kg} / \mathrm{human} \text { weight in } \mathrm{kg})^{0.33}$ ] into account (27), the dose of lurasidone $(10 \mathrm{mg} / \mathrm{kg})$ administered to the mice ( $\sim 25 \mathrm{~g}$ body weight) in this study corresponds to $\sim 0.77 \mathrm{mg} / \mathrm{kg}$ in humans ( $\sim 00 \mathrm{~kg}$ body weight), which is within the range of the clinically used dose for humans (20$60 \mathrm{mg} /$ day: $0.33-1 \mathrm{mg} / \mathrm{kg}$ for humans with $60 \mathrm{~kg}$ body weight). Thus, in this study, lurasidone exerted an antitumor 
A549

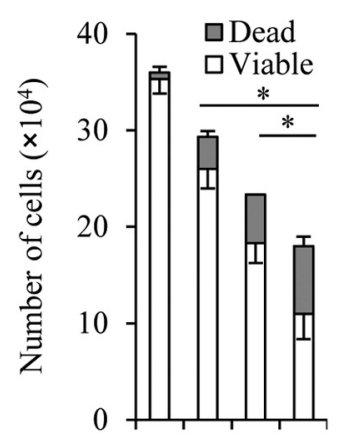

OSI -+-+

Lura -++

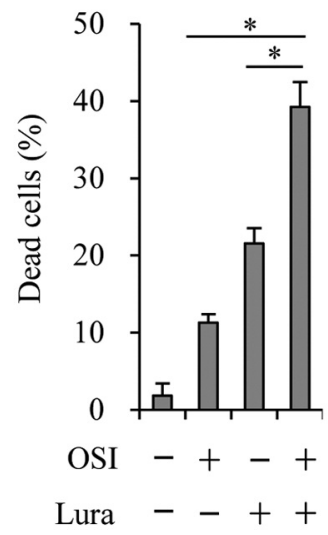

A549 CSLC

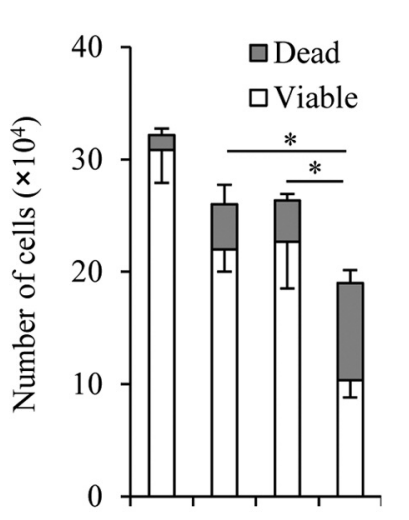

OSI -+-+
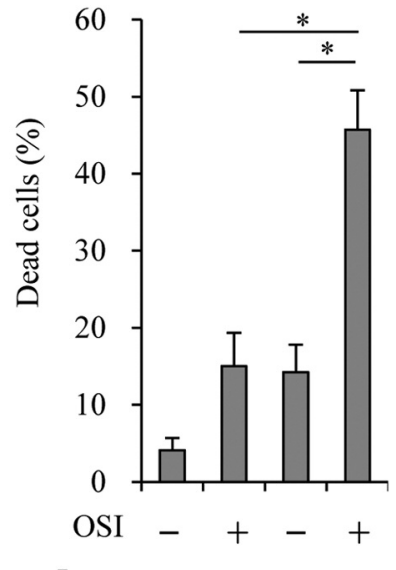

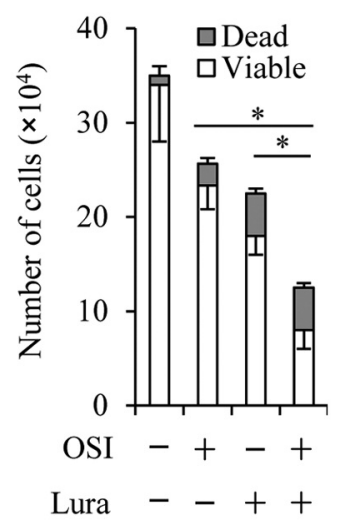

PANC-1

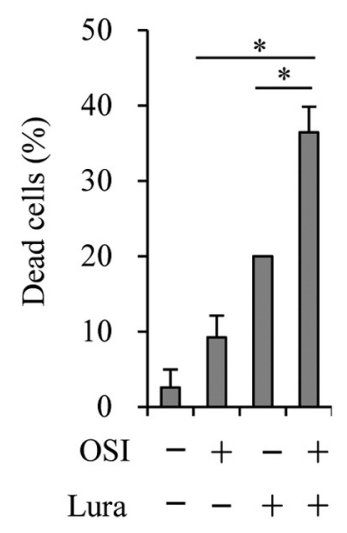

PANC-1 CSLC

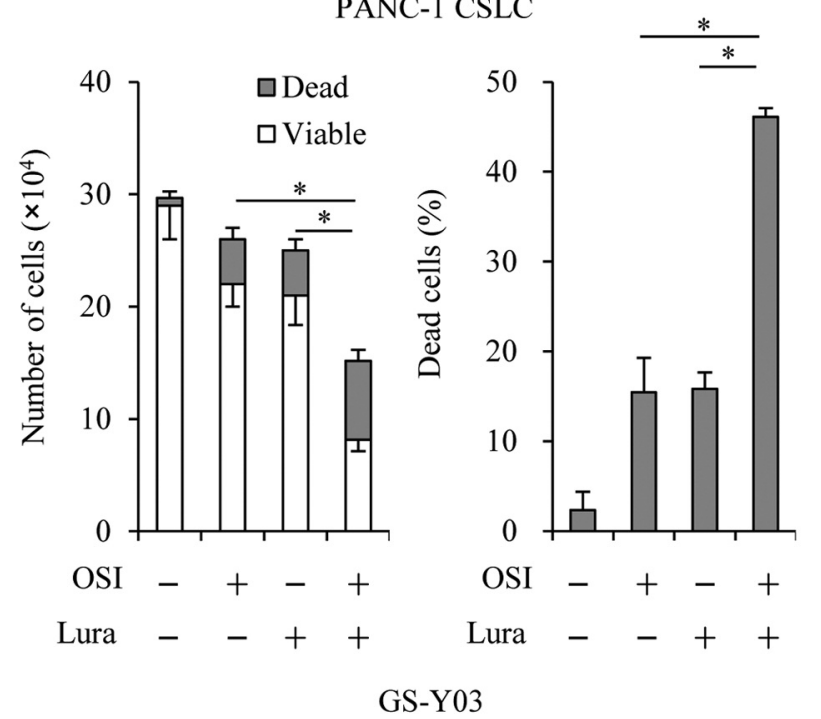

GS-NCC01

GS-Y03
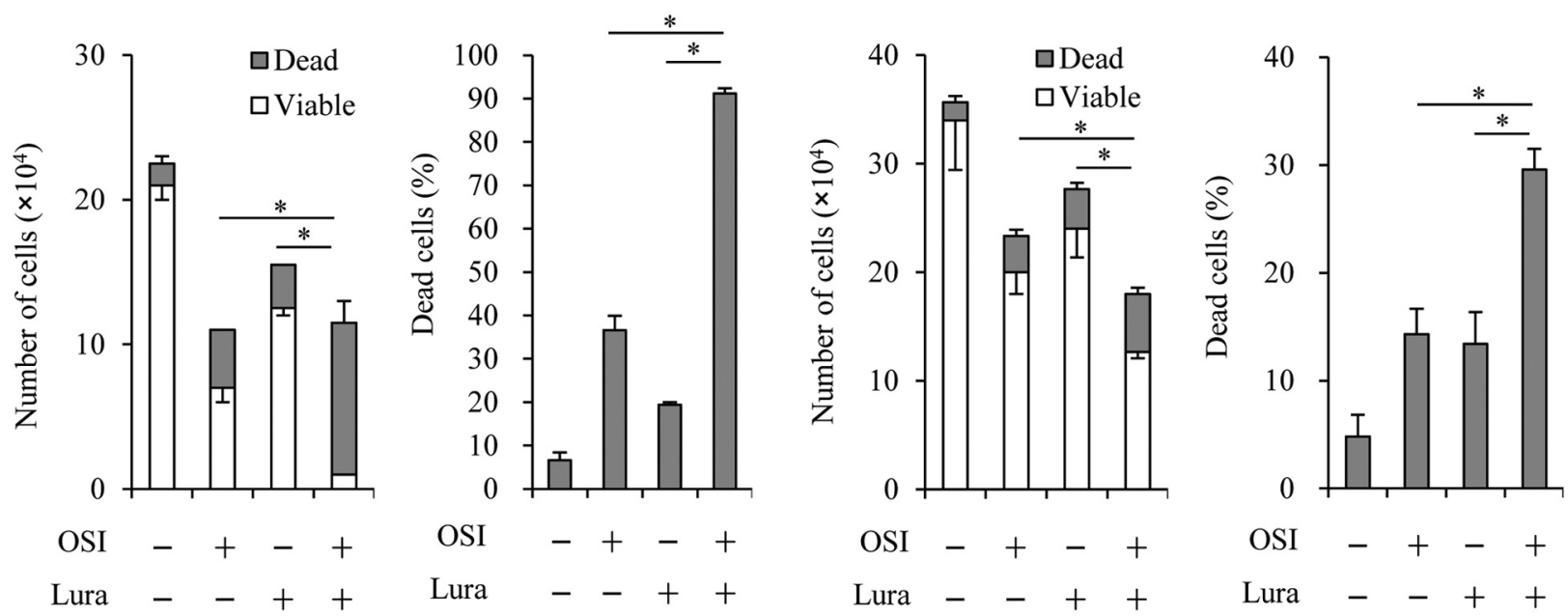

Figure 1. Lurasidone sensitizes various tumor cells to osimertinib. The indicated cancer cells were cultured with or without 2 $\mu M$ osimertinib (OSI) and with or without $5 \mu \mathrm{M}$ lurasidone (Lura) for 3 days (lurasidone concentration was $3 \mu M$ for GS-NCCO1), and then subjected to cell viability assay using trypan blue. The initial cell number was $1 \times 10^{5}$ cells. The total number of cells (viable and dead) (left panels) and percentage of dead cells (right panels) are shown. Values represent means \pm SD from quadruplicate samples of a representative experiment repeated three times with similar results. ${ }^{*} p<0.05$. In the left panels, the number of viable cells was compared. 

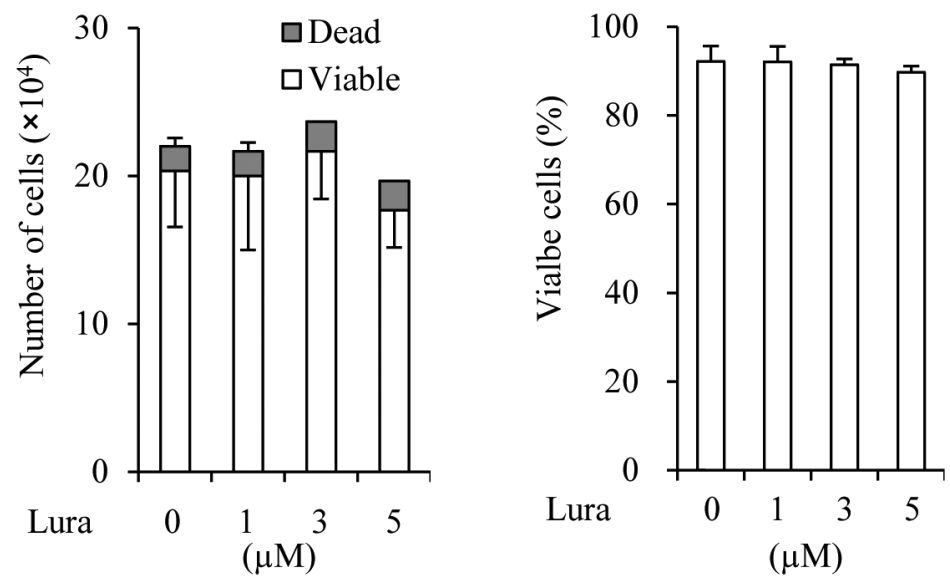

Figure 2. Lurasidone has minimal cytotoxicity to normal human fibroblasts. IMR-90 cells were cultured with lurasidone (Lura) at the indicated concentration for 3 days, and then subjected to cell viability assay with trypan blue. The initial cell number was $1 \times 10^{5}$ cells. The total number of cells (viable and dead) (left panel) and percentage of viable cells (right panel) are shown. Values represent means $\pm S D$ from quadruplicate samples of a representative experiment repeated three times with similar results.

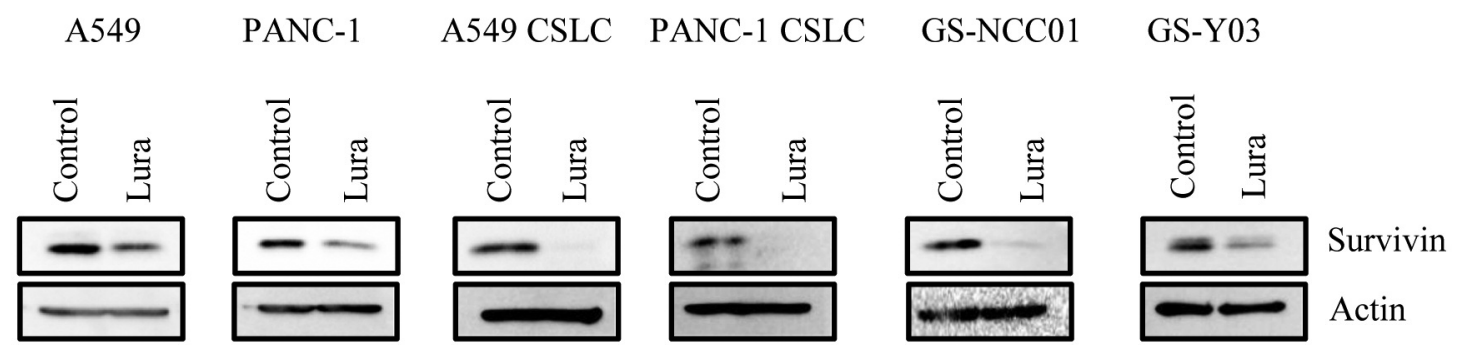

Figure 3. Lurasidone reduces the expression of survivin in cancer cells. Cancer cells were cultured with or without $5 \mu M$ lurasidone (Lura) (lurasidone concentration was $3 \mu \mathrm{M}$ for GS-NCC01) for 3 days, and then subjected to immunoblot analysis.

effect in mice at a clinically relevant dose in combination with osimertinib.

To our knowledge, there are no studies to date that demonstrated the possibility of repurposing lurasidone for the treatment of cancer. While our findings were novel, we were unable to determine the detailed molecular mechanisms of action. Although our analysis may not be complete, our findings suggest that one of the possible mechanisms by which lurasidone sensitizes cancer cells to osimertinib is via reduction of survivin expression.

Resistance to EGFR-TKIs, such as osimertinib, is mediated by various mechanisms including increased expression of cMET (20). The role of survivin, one of the anti-apoptotic factors, has been also indicated to mediate resistance $(22,23)$. Survivin is increasingly being recognized as an important target for cancer treatment, and a number of preclinical and clinical studies are currently being conducted. Recently, the combination of first-generation EGFR-TKI (erlotinib) and a small molecule inhibitor of survivin (YM155) was tested in a clinical trial and its initial results are promising (28).

Our findings also suggested that lurasidone partially sensitizes cancer cells to osimertinib by increasing autophagy. Autophagy can have various roles as it may be suppressed or increased depending on the phase of tumor formation and the actual state of the tumors $(29,30)$. In accordance with our findings, some studies suggest that increased autophagy leads to cell death following EGFR-TKI treatment $(18,31)$. However, other studies suggest that inhibition of autophagy leads to sensitization of cells to EGFR-TKIs (32-34), and that EGFR-TKIs activate autophagy to suppress cell death (35). Thus, there is no consensus as to how EGFR-TKIs and autophagy interact. Our findings demonstrated limited involvement of autophagy; thus, future studies are needed to better understand this possible mechanism.

Lurasidone targets a wide spectrum of receptors for biogenic amines, including serotonin, dopamine, and 
A

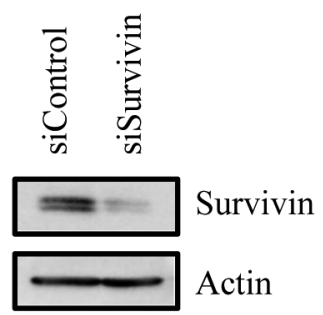

B

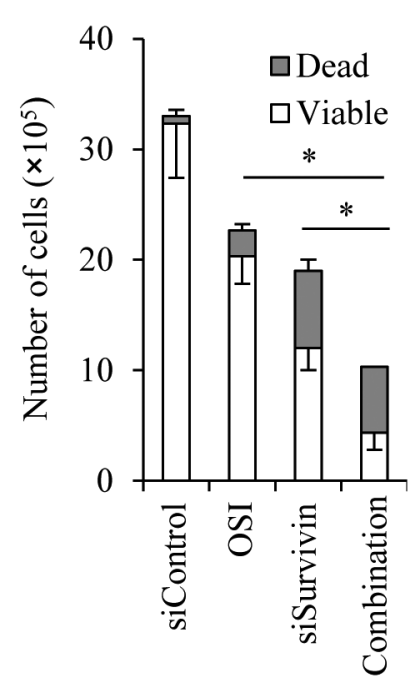

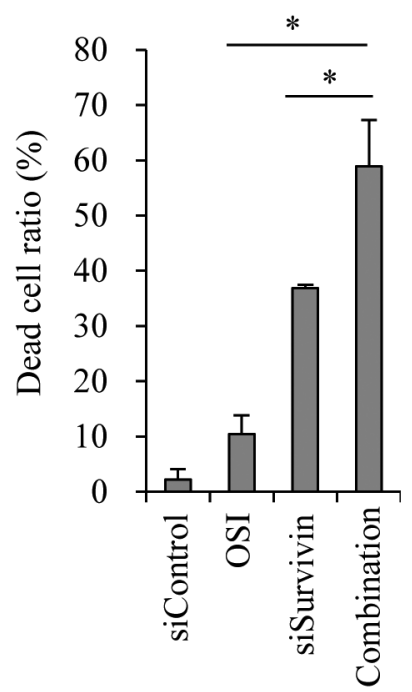

Figure 4. Knock-down of survivin sensitizes cancer cells to osimertinib. Non-targeting siRNA (siControl) or either of the siRNAs against survivin (siSurvivin; siSurvivin\#2) were introduced to A549 cells for 3 days. In (A), the cells were subjected to immunoblotting analysis of survivin expression. Then, in (B), the transfected cells were cultured with or without $2 \mu \mathrm{M}$ osimertinib (OSI) for 3 days, and the cells were then subjected to cell viability assay with trypan blue dye. The initial cell number (after knockdown) was $1 \times 10^{5}$ cells. Values represent means \pm SD from triplicate samples of a representative experiment repeated three times using two siRNAs (siSurvivin\#2 and \#3) with similar results. ${ }^{*} p<0.05$ (comparing viable cells in the left panel).

A

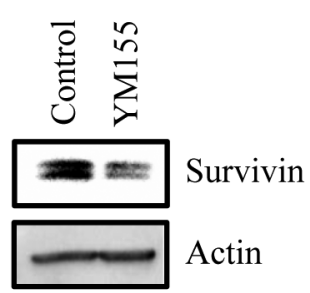

B

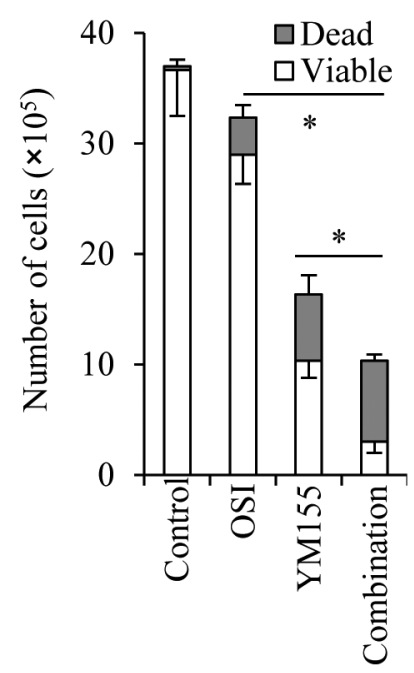

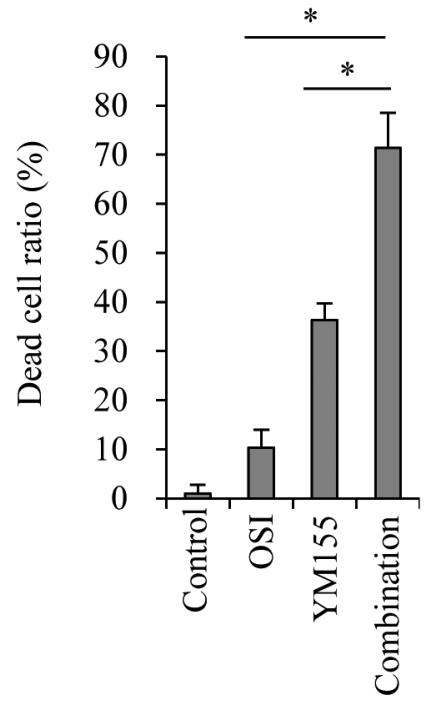

Figure 5. YM155, a pharmacological suppressor of survivin, further sensitizes cancer cells to Osimertinib. A549 cells were treated with 10 nM YM155 for 3 days. In (A), the cells were subjected to immunoblot of survivin expression. Then, in (B), the cells were cultured with or without 10 $n M$ YM155 and with or without $2 \mu M$ osimertinib (OSI) for 3 days, and the cells were then subjected to cell viability assay with trypan blue. The initial cell number was $1 \times 10^{5}$. Values represent means $\pm S D$ from triplicate samples of a representative experiment repeated three times with similar results. ${ }^{*} p<0.05$ (comparing viable cells in the left panel). 
A

A549 PANC-1 A549 CSLC PANC-1 CSLC GS-NCC01 GS-Y03
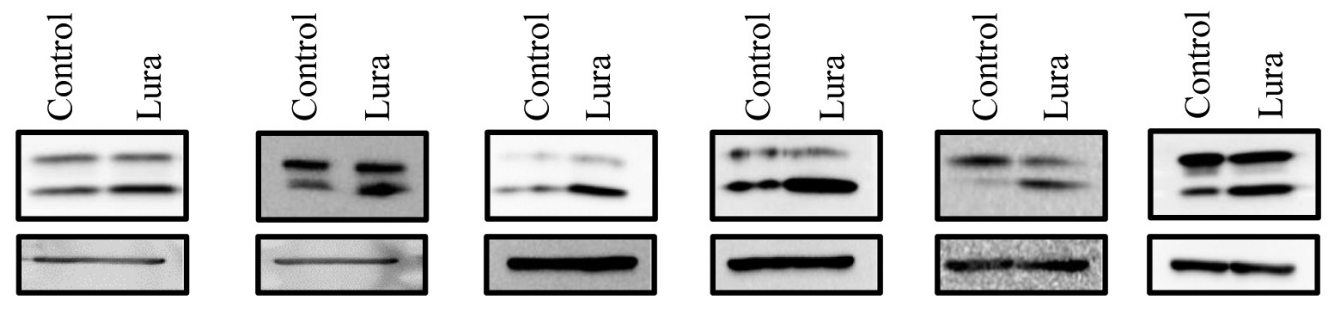

LC3

Actin
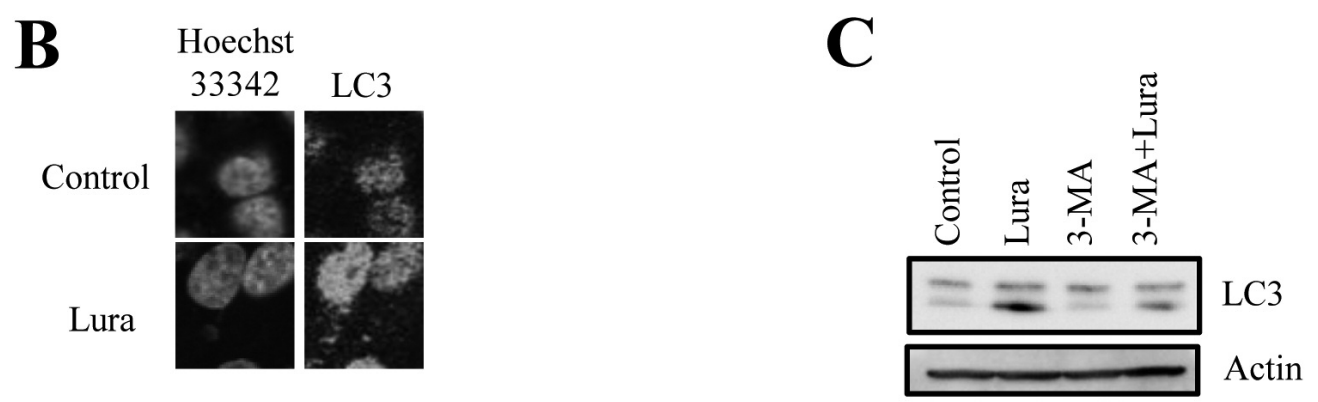

\section{$\mathbf{D}$}
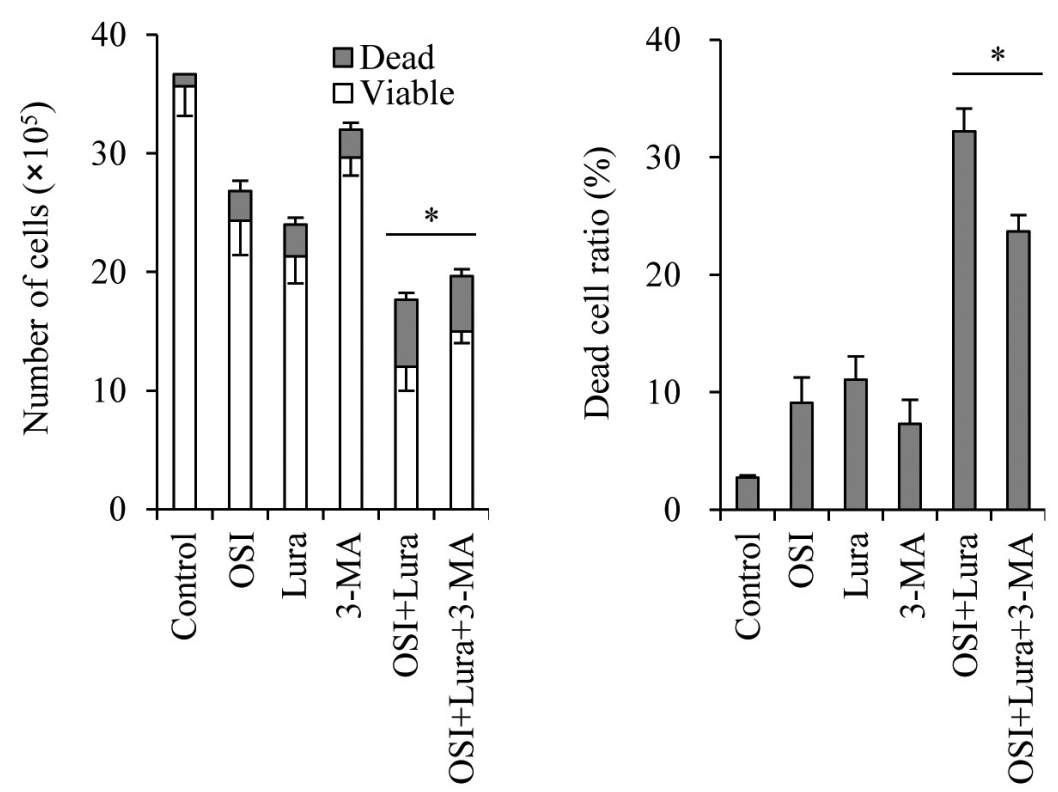

Figure 6. Lurasidone slightly increases autophagy. Cells were treated with or without $5 \mu M$ lurasidone (Lura) for 3 days, and then subjected to the immunoblotting (A). In (B), A549 cells were treated with or without $5 \mu M$ Lura for 3 days, and then subjected to an immunofluorescence analysis of Hoechst33342 and LC3. And next, A549 cells were treated with or without $5 \mu$ M Lura and with or without 0.5 mM 3-methyladenine (3-MA) for 3 days, and then subjected to an immunoblot analysis (C). Lastly, A549 cells were treated with or without $5 \mu M$ Lura, with or without $2 \mu M$ osimertinib (OSI) and with or without $0.5 \mathrm{mM} 3-\mathrm{MA}$ for 3 days, and the numbers of viable and dead cells (left panel), the percentage of dead cells (right panel) were assessed. Values represent the means $\pm S D$ of triplicate samples of a representative experiment repeated with similar results. *p $<0.05$ (comparing viable cells in the left panel). 


\section{A}

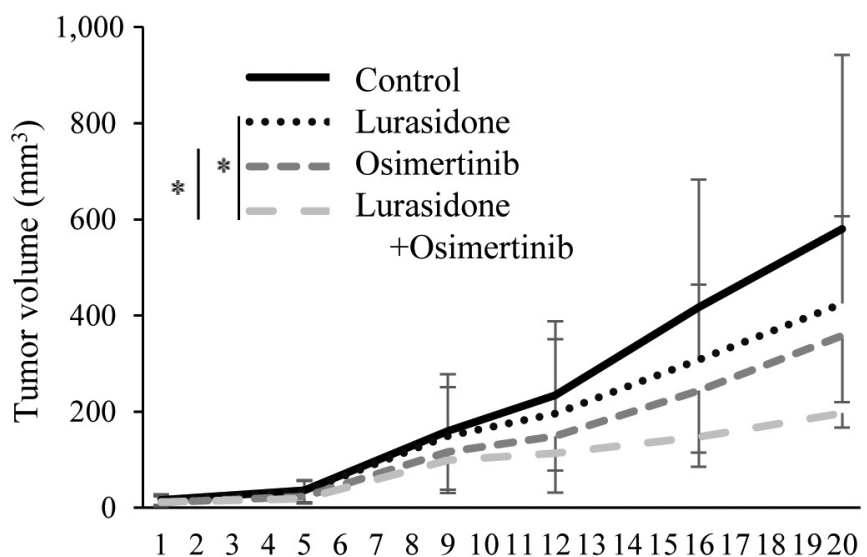

Days after randomization

B

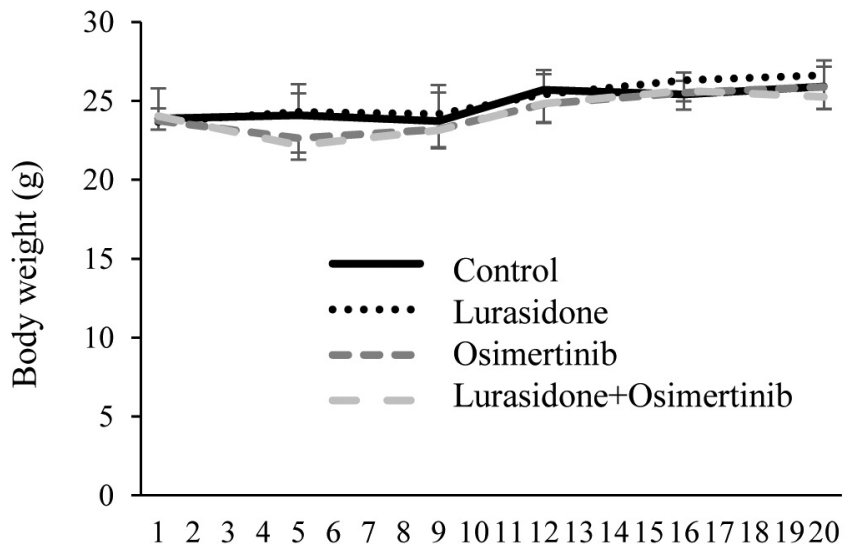

Days after randomization

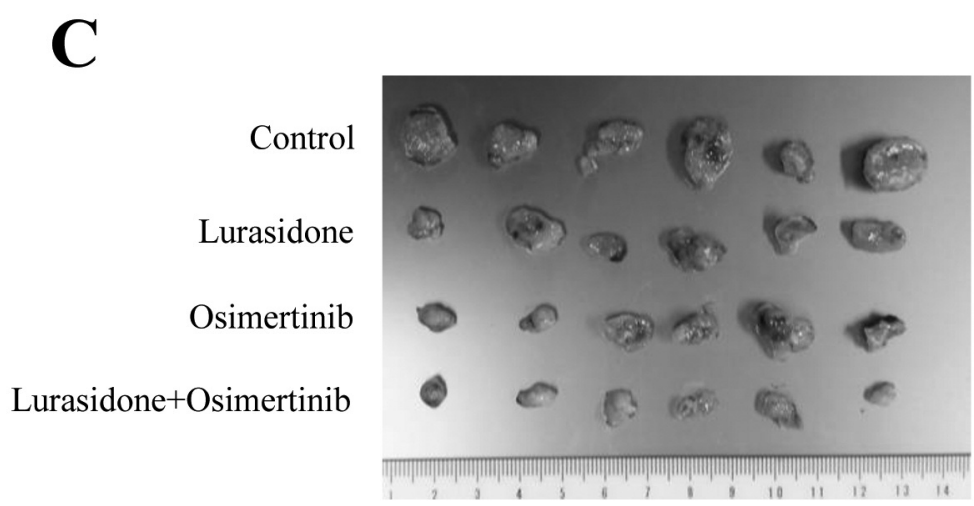

Figure 7. Simultaneous administration of lurasidone and osimertinib sensitizes tumors to osimertinib in vivo. A549 CSCLs (1 $\times 10^{5}$ cells) were subcutaneously implanted into the bilateral flank regions of nude mice. After confirming tumor formation (approximately 25 mm ${ }^{3}$ ), the mice were randomized into groups bearing tumors of a similar volume and the indicated drugs (10 mg/kg of lurasidone five times a week, $5 \mathrm{mg} / \mathrm{kg}$ of osimertinib 5 times a week, or both) were orally administered. In panel (A), the tumor volume of each group is shown ( $n=6$, each group). In (B), the body weight of the mice is presented. In $(C)$, the photo of the tumors excised 20 days after randomization is shown. ${ }^{*} p<0.05$, comparison at the end of the study. 
adrenaline. Therefore, it is difficult to determine the specific molecular mechanisms of lurasidone's anticancer effects. We have reported that brexpiprazole, an antagonist of D2 dopaminergic receptor, suppresses the expression of survivin and sensitizes cancer cells to osimertinib (13). Meanwhile, we have reported that doxazosin, an alpha 1adrenergic receptor antagonist, induces autophagy and sensitizes cancer cells to osimertinib (18). Because these drugs in our past reports share the receptor targets with lurasidone, survivin suppression and autophagy induction by lurasidone might be mediated by the inhibition of $\mathrm{D}_{2}$ and alpha 1-adrenergic receptors, respectively although further studies are required.

To our knowledge, there has been little evidence in the literature to suggest an association between autophagy and survivin, which is an anti-apoptotic molecule. Nevertheless, some studies demonstrated that reduced expression of survivin leads to activation of autophagy in some cancer types (36-38). Other studies demonstrated that autophagy and survivin independently modulate therapeutic effects (39), and that autophagy suppresses the expression of survivin (40). Although it seems unlikely that there is a direct association between survivin and autophagy, future studies are needed as they are both promising targets for cancer treatment.

There are several limitations to this study. Importantly, we were unable to identify particular receptor signaling pathways among the many points of action of lurasidone that play an important role in sensitizing cells to osimertinib. This was due to the difficulty in obtaining agonists and antagonists that are specific to receptor subtypes, such as 5 $\mathrm{HT}_{7}$ agonists and antagonists, as they have an unknown mechanism of action in humans. Furthermore, it is difficult to reproduce the reaction and block the expression in neurotransmitters such as dopamine and 5-HT. The points of action of lurasidone may be off-target and not restricted to neurotransmitter receptors. Thus, further examinations are required.

In conclusion, our findings in vitro and in vivo suggest that lurasidone may sensitize various cancer cells to osimertinib. Reduced expression of survivin and increased autophagy may play a role in sensitizing cells to osimertinib.

\section{Conflicts of Interest}

The Authors declare no conflicts of interest

\section{Authors' Contributions}

S. Suzuki, M.Y. and C.K. designed the research. S. Suzuki performed the experiments. S. Seino and A.S. provided resources. Project administration was C.K.. S Suzuki, M.Y. and C.K. wrote the original paper, and S. Suzuki., M.Y., T.S., K.T., S. Seino., A.S., T.Y., M.O., and C.K. reviewed and edited paper. All Authors discussed the results and contributed to the final manuscript.

\section{Acknowledgements}

This study was supported by a Grant-in-Aid for Scientific Research from the Ministry of Education, Culture, Sports, Science, and Technology of Japan and by Takeda Science Foundation.

\section{References}

1 Siegel RL, Miller KD and Jemal A: Cancer statistics, 2019. CA Cancer J Clin 69(1): 7-34, 2019. PMID: 30620402. DOI: 10.3322/caac. 21551

2 Doebele RC, Drilon A, Paz-Ares L, Siena S, Shaw AT, Farago AF, Blakely CM, Seto T, Cho BC, Tosi D, Besse B, Chawla SP, Bazhenova L, Krauss JC, Chae YK, Barve M, Garrido-Laguna I, Liu SV, Conkling P, John T, Fakih M, Sigal D, Loong HH, Buchschacher GL Jr, Garrido P, Nieva J, Steuer C, Overbeck TR, Bowles DW, Fox E, Riehl T, Chow-Maneval E, Simmons B, Cui N, Johnson A, Eng S, Wilson TR, Demetri GD and trial investigators: Entrectinib in patients with advanced or metastatic NTRK fusion-positive solid tumours: integrated analysis of three phase 1-2 trials. Lancet Oncol 21(2): 271-282, 2020. PMID: 31838007. DOI: 10.1016/S1470-2045(19)30691-6

3 Peters S, Camidge DR, Shaw AT, Gadgeel S, Ahn JS, Kim DW, Ou SI, Pérol M, Dziadziuszko R, Rosell R, Zeaiter A, Mitry E, Golding S, Balas B, Noe J, Morcos PN, Mok T and ALEX Trial Investigators: Alectinib versus crizotinib in untreated ALKpositive non-small-cell lung cancer. N Engl J Med 377(9): 829838, 2017. PMID: 28586279. DOI: 10.1056/NEJMoa1704795

4 Soria JC, Ohe Y, Vansteenkiste J, Reungwetwattana T, Chewaskulyong B, Lee KH, Dechaphunkul A, Imamura F, Nogami N, Kurata T, Okamoto I, Zhou C, Cho BC, Cheng Y, Cho EK, Voon PJ, Planchard D, Su WC, Gray JE, Lee SM, Hodge R, Marotti M, Rukazenkov Y, Ramalingam SS and FLAURA Investigators: Osimertinib in untreated EGFR-mutated advanced non-small-cell lung cancer. N Engl J Med 378(2): 113125, 2018. PMID: 29151359. DOI: 10.1056/NEJMoa1713137

5 Mok TS, Wu Y-L, Ahn M-J, Garassino MC, Kim HR, Ramalingam SS, Shepherd FA, He Y, Akamatsu H, Theelen WS, Lee CK, Sebastian M, Templeton A, Mann H, Marotti M, Ghiorghiu S, Papadimitrakopoulou VA and AURA3 Investigators: Osimertinib or platinum-pemetrexed in EGFR T790M-positive lung cancer. N Engl J Med 376(7): 629-640, 2017. PMID: 27959700. DOI: 10.1056/NEJMoa1612674

6 Wu YL, Ahn MJ, Garassino MC, Han JY, Katakami N, Kim HR, Hodge R, Kaur P, Brown AP, Ghiorghiu D, Papadimitrakopoulou VA and Mok TSK: CNS efficacy of osimertinib in patients with T790M-positive advanced non-small-cell lung cancer: Data from a randomized Phase III trial (AURA3). J Clin Oncol 36(26): 27022709, 2018. PMID: 30059262. DOI: 10.1200/JCO.2018.77.9363

7 Moore MJ, Goldstein D, Hamm J, Figer A, Hecht JR, Gallinger S, Au HJ, Murawa P, Walde D, Wolff RA, Campos D, Lim R, Ding K, Clark G, Voskoglou-Nomikos T, Ptasynski M, Parulekar W and National Cancer Institute of Canada Clinical Trials Group: Erlotinib plus gemcitabine compared with gemcitabine alone in patients with advanced pancreatic cancer: a phase III trial of the National Cancer Institute of Canada Clinical Trials Group. J Clin Oncol 25(15): 1960-1966, 2007. PMID: 17452677. DOI: $10.1200 / J C O .2006 .07 .9525$

8 Fornaro M, De Berardis D, Perna G, Solmi M, Veronese N, Orsolini L, Buonaguro EF, Iasevoli F, Köhler CA, Carvalho AF and de 
Bartolomeis A: Lurasidone in the treatment of bipolar depression Systematic review of systematic reviews. Biomed Res Int 2017: 3084859, 2017. PMID: 28573138. DOI: 10.1155/2017/3084859

9 Massie MJ: Prevalence of depression in patients with cancer. J Natl Cancer Inst Monogr (32): 57-71, 2004. PMID: 15263042. DOI: $10.1093 /$ jncimonographs/lgh014

10 Suzuki S, Okada M, Kuramoto K, Takeda H, Sakaki H, Watarai H, Sanomachi T, Seino S, Yoshioka T and Kitanaka C: Aripiprazole, an antipsychotic and partial dopamine agonist, inhibits cancer stem cells and reverses chemoresistance. Anticancer Res 36(10): 51535161, 2016. PMID: 27798875. DOI: 10.21873/anticanres.11085

11 Sanomachi T, Suzuki S, Kuramoto K, Takeda H, Sakaki H, Togashi K, Seino S, Yoshioka T, Okada M and Kitanaka C: Olanzapine, an atypical antipsychotic, inhibits survivin expression and sensitizes cancer cells to chemotherapeutic agents. Anticancer Res 37(11): 6177-6188, 2017. PMID: 29061799. DOI: 10.21873/ anticanres.12067

12 Suzuki S, Yamamoto M, Togashi K, Sanomachi T, Sugai A, Seino S, Yoshioka T, Kitanaka C and Okada M: In vitro and in vivo anti-tumor effects of brexpiprazole, a newly-developed serotonin-dopamine activity modulator with an improved safety profile. Oncotarget 10(37): 3547-3558, 2019. PMID: 31191825. DOI: $10.18632 /$ oncotarget 26949

13 Suzuki S, Yamamoto M, Sanomachi T, Togashi K, Sugai A, Seino S, Yoshioka T, Kitanaka C and Okada M: Brexpiprazole, a serotonin-dopamine activity modulator, can sensitize glioma stem cells to osimertinib, a third-generation EGFR-TKI, via survivin reduction. Cancers (Basel) 11(7): 947, 2019. PMID: 31284441. DOI: 10.3390/cancers 11070947

14 Sanomachi T, Suzuki S, Togashi K, Seino S, Yoshioka T, Kitanaka C, Okada M and Yamamoto M: Brexpiprazole reduces survivin and reverses EGFR tyrosine kinase inhibitor resistance in lung and pancreatic cancer. Anticancer Res 39(9): 4817-4828, 2019. PMID: 31519584. DOI: 10.21873/anticanres. 13667

15 Okada M, Shibuya K, Sato A, Seino S, Watanabe E, Suzuki S, Seino $M$ and Kitanaka C: Specific role of JNK in the maintenance of the tumor-initiating capacity of A549 human non-small cell lung cancer cells. Oncol Rep 30(4): 1957-1964, 2013. PMID: 23912840. DOI: 10.3892/or.2013.2655

16 Suzuki S, Okada M, Shibuya K, Seino M, Sato A, Takeda H, Seino S, Yoshioka T and Kitanaka C: JNK suppression of chemotherapeutic agents-induced ROS confers chemoresistance on pancreatic cancer stem cells. Oncotarget 6(1): 458-470, 2015. PMID: 25473894. DOI: 10.18632/oncotarget.2693

17 Matsuda K, Sato A, Okada M, Shibuya K, Seino S, Suzuki K, Watanabe E, Narita Y, Shibui S, Kayama T and Kitanaka C: Targeting JNK for therapeutic depletion of stem-like glioblastoma cells. Sci Rep 2: 516, 2012. PMID: 22816039. DOI: $10.1038 /$ srep00516

18 Suzuki S, Yamamoto M, Sanomachi T, Togashi K, Sugai A, Seino S, Okada M, Yoshioka T and Kitanaka C: Doxazosin, a classic alpha 1-adrenoceptor antagonist, overcomes osimertinib resistance in cancer cells via the upregulation of autophagy as drug repurposing. Biomedicines 8(8): 273, 2020. PMID: 32764319. DOI: 10.3390/biomedicines 8080273

19 Shibuya K, Okada M, Suzuki S, Seino M, Seino S, Takeda H and Kitanaka C: Targeting the facilitative glucose transporter GLUT1 inhibits the self-renewal and tumor-initiating capacity of cancer stem cells. Oncotarget 6(2): 651-661, 2015. PMID: 25528771. DOI: $10.18632 /$ oncotarget. 2892
20 Engelman JA, Zejnullahu K, Mitsudomi T, Song Y, Hyland C, Park JO, Lindeman N, Gale CM, Zhao X, Christensen J, Kosaka T, Holmes AJ, Rogers AM, Cappuzzo F, Mok T, Lee C, Johnson BE, Cantley LC and Jänne PA: MET amplification leads to gefitinib resistance in lung cancer by activating ERBB3 signaling. Science 316(5827): 1039-1043, 2007. PMID: 17463250. DOI: $10.1126 /$ science. 1141478

21 Thress KS, Paweletz CP, Felip E, Cho BC, Stetson D, Dougherty B, Lai Z, Markovets A, Vivancos A, Kuang Y, Ercan D, Matthews SE, Cantarini M, Barrett JC, Jänne PA and Oxnard GR: Acquired EGFR C797S mutation mediates resistance to AZD9291 in nonsmall cell lung cancer harboring EGFR T790M. Nat Med 21(6): 560-562, 2015. PMID: 25939061. DOI: 10.1038/nm.3854

22 Morgillo F, Woo JK, Kim ES, Hong WK and Lee HY: Heterodimerization of insulin-like growth factor receptor/epidermal growth factor receptor and induction of survivin expression counteract the antitumor action of erlotinib. Cancer Res 66(20): 10100-10111, 2006. PMID: 17047074. DOI: 10.1158/00085472.CAN-06-1684

23 Dai CH, Shu Y, Chen P, Wu JN, Zhu LH, Yuan RX, Long WG, Zhu YM and Li J: YM155 sensitizes non-small cell lung cancer cells to EGFR-tyrosine kinase inhibitors through the mechanism of autophagy induction. Biochim Biophys Acta Mol Basis Dis 1864(12): 3786-3798, 2018. PMID: 30315932. DOI: 10.1016/j.bbadis.2018.10.015

24 DelBello MP, Goldman R, Phillips D, Deng L, Cucchiaro J and Loebel A: Efficacy and safety of lurasidone in children and adolescents with bipolar I depression: A double-blind, placebocontrolled study. J Am Acad Child Adolesc Psychiatry 56(12): 1015-1025, 2017. PMID: 29173735. DOI: 10.1016/j.jaac.2017. 10.006

25 Jin G, Fu C, Zhao H, Cui K, Chang J and Wong ST: A novel method of transcriptional response analysis to facilitate drug repositioning for cancer therapy. Cancer Res 72(1): 33-44, 2012. PMID: 22108825. DOI: 10.1158/0008-5472.CAN-11-2333

26 Masuda T, Tsuruda Y, Matsumoto Y, Uchida H, Nakayama KI and Mimori K: Drug repositioning in cancer: The current situation in Japan. Cancer Sci 111(4): 1039-1046, 2020. PMID: 31957175. DOI: $10.1111 /$ cas. 14318

27 FDA, Guidance for Industry: Estimating the Maximum Safe Starting Dose in Initial Clinical Trials for Therapeutics in Adult Healthy Volunteers, 2005. Available at: https://www.fda.gov/regulatoryinformation/search-fda-guidance-documents/estimating-maximumsafe-starting-dose-initial-clinical-trials-therapeutics-adult-healthyvolunteers [Last accessed on July 8, 2021]

28 Shimizu T, Nishio K, Sakai K, Okamoto I, Okamoto K, Takeda M, Morishita $M$ and Nakagawa K: Phase I safety and pharmacokinetic study of YM155, a potent selective survivin inhibitor, in combination with erlotinib in patients with EGFR TKI refractory advanced non-small cell lung cancer. Cancer Chemother Pharmacol 86(2): 211-219, 2020. PMID: 32638093. DOI: $10.1007 / \mathrm{s} 00280-020-04112-1$

29 White E and DiPaola RS: The double-edged sword of autophagy modulation in cancer. Clin Cancer Res 15(17): 5308-5316, 2009. PMID: 19706824. DOI: 10.1158/1078-0432.CCR-07-5023

30 Verma AK, Bharti PS, Rafat S, Bhatt D, Goyal Y, Pandey KK, Ranjan S, Almatroodi SA, Alsahli MA, Rahmani AH, Almatroudi A and Dev K: Autophagy paradox of cancer: Role, regulation, and duality. Oxid Med Cell Longev 2021: 8832541, 2021. PMID: 33628386. DOI: 10.1155/2021/8832541 
31 Chen P, Huang HP, Wang Y, Jin J, Long WG, Chen K, Zhao XH, Chen $\mathrm{CG}$ and $\mathrm{Li} \mathrm{J}$ : Curcumin overcome primary gefitinib resistance in non-small-cell lung cancer cells through inducing autophagy-related cell death. J Exp Clin Cancer Res 38(1): 254, 2019. PMID: 31196210. DOI: 10.1186/s13046-019-1234-8

32 Zou Y, Ling YH, Sironi J, Schwartz EL, Perez-Soler R and Piperdi B: The autophagy inhibitor chloroquine overcomes the innate resistance of wild-type EGFR non-small-cell lung cancer cells to erlotinib. J Thorac Oncol 8(6): 693-702, 2013. PMID: 23575415. DOI: 10.1097/JTO.0b013e31828c7210

33 Liu JT, Li WC, Gao S, Wang F, Li XQ, Yu HQ, Fan LL, Wei W, Wang $\mathrm{H}$ and Sun GP: Autophagy inhibition overcomes the antagonistic effect between gefitinib and cisplatin in epidermal growth factor receptor mutant non-small-cell lung cancer cells Clin Lung Cancer 16(5): e55-e66, 2015. PMID: 25979647. DOI: 10.1016/j.cllc.2015.03.006

34 Gorzalczany Y, Gilad Y, Amihai D, Hammel I, Sagi-Eisenberg R and Merimsky O: Combining an EGFR directed tyrosine kinase inhibitor with autophagy-inducing drugs: a beneficial strategy to combat non-small cell lung cancer. Cancer Lett 310(2): 207-215, 2011. PMID: 21807458. DOI: 10.1016/j.canlet.2011.07.002

35 Han W, Pan H, Chen Y, Sun J, Wang Y, Li J, Ge W, Feng L, Lin $X$, Wang $X$, Wang $X$ and Jin H: EGFR tyrosine kinase inhibitors activate autophagy as a cytoprotective response in human lung cancer cells. PLoS One 6(6): e18691, 2011. PMID: 21655094. DOI: 10.1371 journal.pone.0018691

36 Chang YJ, Li LT, Chen HA, Hung CS and Wei PL: Silencing survivin activates autophagy as an alternative survival pathway in HCC cells. Tumour Biol 35(10): 9957-9966, 2014. PMID: 25008566. DOI: $10.1007 / \mathrm{s} 13277-014-2257-6$
37 Wang YF, Zhang W, He KF, Liu B, Zhang L, Zhang WF, Kulkarni AB, Zhao YF and Sun ZJ: Induction of autophagydependent cell death by the survivin suppressant YM155 in salivary adenoid cystic carcinoma. Apoptosis 19(4): 748-758, 2014. PMID: 24370995. DOI: 10.1007/s10495-013-0960-1

38 Cheng SM, Chang YC, Liu CY, Lee JY, Chan HH, Kuo CW, Lin KY, Tsai SL, Chen SH, Li CF, Leung E, Kanwar JR, Huang CC, Chang JY and Cheung CH: YM155 down-regulates survivin and XIAP, modulates autophagy and induces autophagy-dependent DNA damage in breast cancer cells. Br J Pharmacol 172(1): 214234, 2015. PMID: 25220225. DOI: 10.1111/bph.12935

39 Wang L, Huang W and Zhan J: Grape seed proanthocyanidins induce autophagy and modulate survivin in HepG2 cells and inhibit xenograft tumor growth in vivo. Nutrients 11(12): 2983, 2019. PMID: 31817589 . DOI: $10.3390 /$ nu11122983

40 Xu YX, Huang C, Liu M, Chen N, Chen W, Yang C, Zhao Y, Li $X$, Duan J, Liu S and Yang S: Survivin regulated by autophagy mediates hyperglycemia-induced vascular endothelial cell dysfunction. Exp Cell Res 364(2): 152-159, 2018. PMID: 29391151. DOI: 10.1016/j.yexcr.2018.01.037
Received May 31, 2021

Revised June 21, 2021

Accepted July 9, 2021 